\title{
A PARTICULARIDADE COMO CATEGORIA ESTÉTICA E AS FRONTEIRAS ENTRE HISTÓRIA E FICÇÃO
}

\section{THE PARTICULARITY AS AESTHETIC CATEGORY AND THE FRONTIERS BETWEEN HISTORY AND FICTION}

\author{
Fatima Rejane de Meneses ${ }^{1}$
}

\begin{abstract}
RESUMO: O objetivo deste trabalho é, com base nos estudos do filósofo e marxista Georg Lukács, analisar a particularidade como categoria estética e as fronteiras entre história e ficção, ou seja, a análise do particular constitui o ponto central organizador do processo da criação estética, sendo a particularidade entendida num campo de forças entre universal e singular e constituindo a base ideal para a verdade artística da forma. Para Lukács, a arte é o reflexo da realidade, e é por meio dela que o homem se humaniza em suas relações sociais. Assim, a tomada de consciência do homem surge sempre da realidade, da relação do sujeito com a realidade, com a vida concreta em movimento. Este texto busca ainda fazer um apanhado geral dos principais conceitos de Lukács sobre a arte uma vez que estes são relevantes no entendimento geral de suas ideias sobre a estética marxista.
\end{abstract}

Palavras-chave: Lukács; Arte; Particularidade; Ficção e História.

ABSTRACT: The objective of this work is based on studies of the philosopher and Marxist Georg Lukács, analyze the particularity as aesthetic category and the boundaries between history and fiction, it means the particular analysis is the centerpiece organizer of aesthetic creation process, being the particularity understood in a field of forces between universal and singular and constitutes an ideal base for artistic truth of the form. For Lukács, art is a reflection of reality, and it is through it that man becomes human in their social relations. Thus, man's awareness always comes up from the reality, the subject's relationship with reality, with the concrete life in motion. This text also seeks to give an overview of the key concepts of Lukács about art as these are relevant in the general understanding of his ideas on Marxist aesthetics.

Keywords: Lukács; Art; Particularity; Fiction and History.

\footnotetext{
${ }^{1}$ Doutoranda da Pós-Graduação em Literatura da Universidade de Brasília (PósLIT/UnB). Mestra em Literatura pela UnB (2013). Especialista em Língua Portuguesa, Licenciada em Letras - Língua Portuguesa e respectiva Literatura pela UnB (1997); e Bacharelado em Comunicação Social - Jornalismo pelo Centro de Ensino Unificado de Brasília (1983). Atualmente é revisora de texto do Centro de Estudos Avançados Multidisciplinares (Ceam), órgão da Fundação Universidade de Brasília (FUB). E-mail: rejanedemeneses@gmail.com
} 


\section{INTRODUÇÃO}

Georg Lukács (13/04/1885-04/06/1971) foi um filósofo húngaro do século XX, historiador literário e crítico marxista cujo trabalho esteve ligado aos ensinamentos de Hegel e ao marxismo, sendo um dos fundadores do marxismo ocidental. Como crítico literário, escreveu teorias sobre o realismo e o romance como gênero literário. Ele aderiu ao marxismo um pouco antes da revolução húngara de 1919, mas já era um intelectual húngaro reconhecido internacionalmente.

A obra de Lukács divide-se em duas fases: 1) a de sua juventude, não materialista, influenciada primordialmente pelas ideias de Hegel, portanto com um viés metafísico e idealista. A esta fase pertence A teoria do romance, que será rejeitada por ele no futuro por considerá-la errônea; 2) a que é considerada marxista, portanto com uma vertente filosófico-materialista da história, em que a arte e a literatura estão no campo das ideologias, fazendo parte da superestrutura da sociedade.

Para a teoria marxista, a sociedade é constituída de infraestrutura e superestrutura. A infraestrutura compreende as forças e as relações de produção, a divisão do trabalho e as relações de propriedade, em que os homens produzem as necessidades e as comodidades da vida. Essas relações determinam outras relações e ideias da sociedade, ou seja, as superestruturas, que incluem a cultura, as instituições, as estruturas de poder político, papel social, rituais e o Estado. A infraestrutura determina a superestrutura. Para o marxismo ortodoxo, a infraestrutura determina a superestrutura em uma relação unidirecional. Contudo, para o pensamento marxista mais avançado essa relação não é estritamente unidirecional, pois a base influencia a superestrutura da mesma forma que esta influencia a infraestrutura.

A dialética e a estética marxista, a ontologia, o materialismo, a arte e o realismo artístico são termos fundamentais nos estudos desse autor e são, indiscutivelmente, assuntos tão complexos e abrangentes que exigem do estudioso e pesquisador de suas ideias o debruçamento constante sobre eles. Assim, para melhor entender e apreender o pensamento de Lukács é necessário analisar alguns desses conceitos, ainda que brevemente, para que então tratemos da particularidade como categoria estética. Vejamos.

O termo dialética, do grego dialektiké, significa debater e persuadir, pelo qual são colocadas em confronto ideias diferentes com a defesa de uma ideia que pode ser 
contradita logo depois. Essa forma de filosofar pretende alcançar a verdade por meio de contraposição e reconciliação de contradições entre a unidade e a multiplicidade, o singular e o universal. Para a dialética marxista, o mundo só pode ser compreendido por meio de ideias contrárias até se chegar à verdade. Marx e Engels mudaram o conceito de Hegel e introduziram um novo conceito, a dialética materialista, que pregava serem os movimentos históricos decorrentes das condições materiais da vida.

A dialética marxista é uma versão hegeliana aplicada ao movimento e às contradições de origem econômica na história da humanidade. Para Hegel, especificamente, ela caracteriza a realidade como um movimento incessante e contraditório dividido em tese, antítese e síntese, manifestado simultaneamente em todos os pensamentos humanos e em todos os fenômenos do mundo material.

Outro conceito trabalhado por Lukács é ontologia - estudo do ser. A filosofia estuda a natureza do ser, a existência e a realidade com o intuito de determinar as categorias fundamentais e as relações do ser enquanto ser. Se a ontologia é o estudo do ser, no marxismo ela está associada à classe social/sociedade de classes, à reificação, ao trabalho humano e ao mercado, ou seja, ao estudo do homem como ser social. Para esse estudioso é também a tomada de consciência do homem.

Quanto ao termo materialismo, essencial na teoria marxista, este representa aquilo que é necessário à sobrevivência do homem em sociedade: alimentação, moradia, trabalho, etc. e que fundamenta a estrutura econômica da sociedade organizada.

Lukács considera o artista um ser social influenciado pelo momento histórico, caracterizado por um processo permanente de mudança e transformação. Nesse sentido, a arte se aproxima mais da vida e da realidade do que a ciência. E ao considerar a relação subjetividade-objetividade, ele acredita que o homem necessita recorrer às formas superiores de objetivação tanto na arte como na ciência, sendo a única maneira de retornar às experiências diárias com maior bagagem de vida, mais enriquecido.

Lukács hesitou um pouco antes de entrar para o Partido Comunista Húngaro em 1918. Contudo, a morte de Lênin - o líder da revolução bolchevique e principal líder da União Soviética - em 21 de janeiro de 1924 priva o marxista de seu principal referencial teórico e prático, sendo grandes também as mudanças na Internacional Comunista.

Os desvios proporcionados pelo comportamento de Stalin, que substituiu Lênin, não são vistos com clareza por Lukács, que se curvava às ações repressivas comandadas 
pelo regime. Em 1928, contudo, ele entra em choque com a linha oficial do movimento comunista. Sobre esse período de sua vida vejamos o que diz Tertulian (2007, p. 4):

A importância do combate conduzido por Georges Lukács durante o primeiro período de sua vida esteve até o presente largamente subestimada. E hoje, após a queda dos regimes carcomidos que não tinham nada em comum com o socialismo a não ser o nome, um fiel a Marx dificilmente seria considerado como um modelo de clarividência. É preciso seguir em seus escritos os traços deste combate para poder julgá-lo.

Para Tertulian (2007, p. 9), Lukács nunca fez mistério de que após a morte de Lênin se aliou a Stalin no sentido de construir um socialismo em um só país:

Admirador do realismo, crítico de vanguarda e defensor do realismo socialista, Lukács não podia escapar à acusação de conformismo estético. Reprovaram-no com frequência não somente de ter feito suas as orientações fundamentais da crítica soviética da época, mas de ter tentado dar a elas as letras de nobreza por meio de suas análises e sua argumentação, que se situavam em um nível sensivelmente diferente daquelas dos escribas stalinistas.

Com o advento do nazismo, Lukács exilou-se na Rússia em 1933. Na época da Guerra Fria, foi criticado pelos mentores da política cultural soviética e húngara. E em 1956, após a denúncia dos crimes de Stalin, retornou à atividade política na Hungria no governo de Imre Nagy.

\section{A particularidade}

Estudemos em especial esse termo central nos estudos de Lukács: a particularidade como categoria estética. Assim se refere Lukács (1970, p. 167):

A análise do particular que constitui o ponto central organizador do processo da criação estética, ainda que em suas consequências ultrapasse os quadros do exame gnosiológico, revela-nos porém, ao mesmo tempo, os traços específicos essenciais do reflexo estético da realidade.

Para Lukács a arte poderia produzir o comprometimento e elevar o grau de consciência dos indivíduos por meio do realismo artístico, sendo esta um reflexo estético ou artístico peculiar e particular da realidade. Muitas vezes são cobradas da arte 
características ou até resultados que não são dela. Esse reflexo, contudo, não é puro ou imediato, mas repleto de mediações. A arte verdadeira não consegue captar os detalhes da vida, o caráter extensivo total. Ela capta um mundo particular e o intensifica e reduz num espaço único, ou seja, nos vários tipos de arte (romance, poema, quadro e outras manifestações artísticas) a extensão da vida cotidiana.

Para Hegel, a arte leva o sujeito para um mundo diferente do cotidiano; para o pensamento lukacsiano, assim como para os marxistas, o trabalho é central na vida do homem, uma vez que este desencadeia a relação do homem com a sociedade, consigo mesmo e com os outros homens. Daí ser o trabalho considerado a exteriorização primária do ser humano, que significa adequar o mundo às suas necessidades.

$\mathrm{Na}$ arte, percebe-se a singularidade da vida (individual, imediata, cotidiana). Ao buscar compreender os fenômenos da vida, o homem depara-se com a relação entre essência e aparência. O reflexo tem de captar a realidade, composta de essência e aparência, ou seja, de elementos importantes (essência) e de elementos instantâneos (aparência), mas a obra de arte não pode fixar-se em nenhum deles, mas na universalidade e na singularidade, pois ambos formam a particularidade, sendo a arte responsável pela conexão entre singularidade e universalidade. A essência é construída; a aparência é imediata. Os dois termos estão intrinsecamente ligados.

Assim, a particularidade é o modo de organizar a vida humana em suas singularidades, e a singularidade, por sua vez, articula-se com a universalidade. No pensamento lukacsiano, a particularidade é entendida num campo de forças entre universal e singular e constitui a base ideal para a verdade artística da forma. É essencial, portanto, que se perceba o particular no universal, pois a particularidade articula-se com o universal e forma a "unidade contraditória". Desse modo, a arte não pode perder nem a singularidade nem a universalidade.

Para Lukács (1970, p. 168), é importante "que esta universalidade não seja abstrata, mas concreta [...], mas esta concreticidade é a concreticidade da máxima universalidade, máximo afastamento - formal - das formas do mundo da evidência imediata". Ele (LUKÁCS, 1970, p. 170) estuda "a forma estética em seu modo genuíno e original de manifestação, tal como podemos encontrá-la, sobretudo na obra de arte, enquanto objetivação do reflexo estético da realidade, no processo criador e no comportamento estético-receptivo em face da arte".

Assim se expressa a estética marxista lukacsiana (1970, p. 168): 
Forma e conteúdo se convertem incessantemente um no outro; se bem que o materialismo dialético e histórico - indo além de Hegel estabeleça firmemente a prioridade do conteúdo, mesmo reconhecendo esta recíproca relação de convergência do conteúdo na forma e viceversa; apesar disso, a investigação que se dirija especificamente para a forma não é absolutamente algo ocioso e, em particular, não é um problema cujo estudo, como pensam os vulgarizadores, entre em choque com o método do materialismo dialético e histórico. $\mathrm{O}$ marxismo professa ainda que a tomada de consciência do homem surge sempre da realidade, ou seja, da relação do sujeito com a realidade, com a vida concreta em movimento.

Hegel (apud LUKÁCS, 1970, p. 168, nota 1) reconhece que o conteúdo não é mais do que o converter-se da forma em conteúdo, e a forma nada mais do que o converter-se do conteúdo em forma.

Ainda sobre a particularidade, diz Lukács (1970, p. 175):

A particularidade, como categoria central da estética, por um lado, determina uma universalização da pura singularidade imediata dos fenômenos da vida, mas, por outro, supera em si toda universalidade; uma universalidade não superada, que transcendesse a particularidade, destruiria a unidade artística da obra.

A particularidade é importante na estética porque cada obra tem em si uma fisionomia individual, pois é qualitativa e individualmente diversa de todas as obras “similares”, embora numa visão imediata possam parecer bastante próximas.

Não se pode deixar de considerar também na obra de arte que a objetividade não pode ser separada da subjetividade nem mesmo numa análise estética mais geral. A subjetividade estaria relacionada à particularidade e à singularidade, enquanto a objetividade estaria mais ligada à categoria da universalização. Da mesma forma, não pode existir nenhum objeto estético sem sujeito estético, sendo a obra de arte o objeto.

Embora haja na obra de arte o particular-individual do artista e esteja presente também a leitura que cada um faz individualmente da obra, no contexto mais universal o entendimento da obra se dá num nível mais coletivo e universal que abarca a trajetória e o conhecimento que o indivíduo adquiriu em seu convívio social. Da mesma forma, o artista transforma a "particularidade individual em generalização estética [...] e isso ocorre como consequência do contato com a realidade objetiva, como consequência do 
esforço de reproduzir fielmente esta realidade, de um modo profundo e verdadeiro" (LUKÁCS, 1970, p. 187).

Cabe ao artista, em especial ao que tem como objeto a literatura, ou seja, o escritor, criar, e para isso muitas vezes tem de se distanciar de situações que fogem à sua lógica interna, aos preconceitos de sua personalidade interior ou de sua ideologia como autor. Assim, tomemos emprestado o que diz Lukács (1970, p. 188):

É decisiva para a estética a necessidade de representar como verdade objetiva, e ao mesmo tempo como um mundo humano, adequado ao homem, uma realidade que existe independentemente da consciência humana. Esta necessidade impõe a referida universalização da subjetividade no particular, bem como a superação de qualquer puro universal na subjetividade humanizada do particular.

Outro termo usado por esse filósofo marxista sobre o reflexo estético da realidade em seu texto sobre particularidade é partidarismo, que significa a tomada de posição do artista em face das lutas históricas do presente no qual ele vive. Dessa forma ele escolhe, exclui, seleciona e universaliza as singularidades imediatas para produzir sua obra, ou seja, o artista elege entre tantos o conteúdo essencial ou significativo com o qual irá trabalhar. Esse partidarismo artístico deve estar representado em cada detalhe e em toda a obra. Visto de outra forma, a originalidade do autor está em empreender uma luta entre o velho e o novo procurando captar os traços decisivos necessários à sua produção. Daí a afirmação que ele faz (1970, p. 199) de que "a tomada de posição é inevitável na obra de arte". Prosseguindo, diz ainda: "De fato, além da emocionalidade partidária sempre necessária (e da qual já falamos), a vida mental do homem [...] é sempre ligada a uma posição afirmativa ou negativa”.

Uma vez que a arte reflete a crítica à vida social, ela levanta as possibilidades de superação bem como as necessidades de solução, cabendo aos seres humanos a possibilidade de mudar os destinos da humanidade. Conforme Lukács (1970, p. 199):

\footnotetext{
A arte, contudo, jamais representa singularidades, mas sim - e sempre - totalidade; ou seja, ela não pode contentar-se em reproduzir homens com suas aspirações, suas propensões e aversões, etc.; deve ir além, deve orientar-se para a representação do destino destas tomadas de posição em seu ambiente histórico-social.
}

Considerando em particular a literatura, o autor toma como assunto, direta ou indiretamente, o destino dos homens e a tomada de posição em face deles decidindo o 
destino ou o fracasso de seus personagens. Nessa decisão já está contida "a crítica do artista ou da obra de arte" (LUKÁCS, 1970, p. 199).

$\mathrm{Na}$ obra de arte, o artista supera tanto o "singular quanto o universal na particularidade", fazendo surgir uma "objetividade unitária”. Desse modo, "as leis da vida se unem inseparavelmente às forças fenomênicas imediatas da vida, penetram nelas até o ponto de ser impossível uma distinção" (LUKÁCS, 1970, p. 201-202).

Para o marxismo, há uma relação intrínseca entre a arte e a vida social. Além disso, a humanidade do homem é um processo em construção, daí não se poder falar de "natureza humana" como algo preexistente. E mais: a arte tem uma missão desfetichizadora, pois ela precisa refletir a realidade, e para ser autêntica ela se coloca como crítica da vida e humanizadora do homem.

No pensamento lukacsiano, o artístico e o científico são reflexos da realidade, pois a realidade é uma só, mas a especificidade do reflexo é que determina a forma como o fenômeno é trabalhado. O reflexo artístico não é imediato, pois o artista faz um recorte da vida, e o mesmo fenômeno é refletido por vários artistas de formas estéticas diferenciadas pelo conteúdo selecionado. Prosseguindo em tal pensamento aparece a ideia do típico, que para ele, filósofo, é central e específico na "encarnação da particularidade na arte e representaria o aspecto assinaladamente particular da realidade e de seu desenvolvimento" (LUKÁCS, 1970, p. 246).

Sobre a oposição entre reflexo científico e reflexo artístico da realidade, Lukács (1970, p. 242) diz que se deve "sublinhar de imediato que - do ponto de vista do conteúdo - o típico, como todos os elementos do conteúdo artístico, é uma categoria da vida que deve também desempenhar um papel, portanto, no reflexo científico, embora não tão central como na arte".

Assim, o típico seria então uma categoria da vida; não é algo que foi produzido ou forjado pela necessidade. O típico é uma particularidade, uma singularidade; não faz parte da "média", mas do particular, do que foi humanizado, uma vez que a arte humaniza o homem, e essa tipicidade (o tipo) surge das ações humanas reunindo o singular e o universal. Desse modo, a obra típica reflete essa humanização do homem de acordo com suas ações. O típico na obra de arte é uma obra como um todo. Assim, há obras que podem ser classificadas como típicas. Por isso "a obra de arte pode e deve ser uma totalidade concluída, uma formação autônoma" e se poder falar ainda em "dialética entre 
necessidade e contingência sob formas inteiramente diversas daquelas que têm lugar no reflexo científico" (LUKÁCS, 1970, p. 248-249).

Desse modo, afirma Lukács (1970, p. 249):

\begin{abstract}
A arte não figura nem a necessidade em si, com suas leis mais universais, nem o contingente em sua crua oposição à necessidade, nem tampouco o contingente superado sem resíduos na necessidade universal. Ela fornece uma reprodução da real oscilação recíproca de necessidade e contingência nas proporções que correspondem à verdade do mundo representado.
\end{abstract}

Não se pode negar, contudo, que, na multiplicidade de gêneros literários que existe, a particularidade do mundo representado esteja submetida às condições históricosociais bem como às personalidades artísticas e ao tipo de obra a ser criado, pois a relação recíproca entre necessidade e contingência evolui com o tempo e com as alterações produzidas no mundo.

Dois outros aspectos relevantes aparecem nos estudos da estética lukacsiana: essência e aparência, havendo entre elas uma relação recíproca, reflexo daquilo que existe na realidade, que é trabalhada de modo diferente pela arte e pela ciência. A arte conserva a estrutura da realidade, dando evidência imediata à essência, enquanto a ciência retorna ao fenômeno após extrair a essência confirmando-lhe a realidade. "Se a aparência é o 'aparecer' da própria essência em si mesma e a essência em uma de suas determinações, em um de seus aspectos, em um de seus momentos" (LUKÁCS, 1970, p. 206), a essência é algo mais profundo e preciso. Como centro do reflexo artístico, a particularidade é o momento da síntese de universalidade e singularidade, mas supera ambos os fenômenos e permite a revelação da essência.

Hegel (apud LUKÁCS, 1970, p. 207) trata da intuição sensível que pertence à arte e diz que ela "confere à verdade a forma de representações sensíveis" e conclui que na arte se expressa o belo, assim definido por ele: "O belo se define, por isto, como o aparecer sensível da ideia”. Lukács ressalta aqui a genialidade de Hegel, que nos conduziu ao justo entendimento do fato estético, mas diz que seus juízos e intuições geniais são sempre deformados pelo seu idealismo.

Para concluir, não se pode deixar de ressaltar que a arte funciona como autoconsciência do desenvolvimento da humanidade e acima de tudo ela humaniza o homem, pois a estética abraça o mundo global tanto externo como interno na sua produção 
artística. É impossível falar do homem dissociado da arte que ele é capaz de produzir ao refletir a realidade.

\section{História e ficção}

Tomemos agora os termos história e ficção para delinear suas diferenças e aproximações. A historiografia, em razão de seu teor discursivo, apresenta semelhanças com a literatura ficcional. Contudo, ela representa a busca dos seres humanos para conhecer seu passado e exige um aporte mais científico, que toma por base dados, documentos, entrevistas, datas e locais em busca da veracidade dos fatos. A história preocupa-se com a objetividade, com os fatos passados, tendo em vista que também é uma ciência. No entanto, nada a impede de se apropriar de um instrumento literário significativo - o discurso. A ficção, por sua vez, trabalha a subjetividade e a imaginação, pois está "descompromissada" com a realidade, utilizando a criação e a fantasia, o que não se permite à historiografia.

Desse modo, é preciso levar em conta que a história e a ficção muitas vezes trabalham com o mesmo objeto, mas cada uma tem maneira própria de estudá-lo, ou seja, nada impede que a ficção utilize os fatos históricos, mas certamente dará a eles outro verniz, uma vez que a história trata dos fatos que realmente ocorreram, considerando um referencial limitado pelos acontecimentos, enquanto a ficção fala dos que podem ocorrer, mesmo que apenas na imaginação do escritor, portanto ilimitados pela sua capacidade criadora. Embora história e ficção sejam ambas formas de narrativa, apresentam características diversas, cada uma possui forma peculiar. A narrativa histórica recupera o passado da humanidade e tem como escopo a objetividade, o compromisso com a verdade dos fatos; a narrativa é construída com base na realidade. A ficção, apesar de poder utilizar um fato histórico, tem como premissa a narrativa irreal, subjetiva, criada pela imaginação, pois seu campo de trabalho é a literatura, que é, além de um fenômeno estético, uma manifestação cultural. Assim, os limites entre história e ficção dependem da abordagem utilizada pelo narrador.

Lavorati e Teixeira (2010) ressaltam em artigo, com base na obra Literatura $e$ história, de Maria Teresa Freitas (1986), que as grandes obras romanescas que tiveram recepção favorável e importante repercussão foram justamente as que tinham como pano 
de fundo acontecimentos históricos. Elas defendem haver um diálogo entre história e ficção dentro do gênero literário romance histórico e afirmam:

O romance histórico clássico surgiu em meio a transformações sociais, políticas e econômicas que trazem à tona, nos indivíduos, a consciência da importância da história e do peso dos seus reflexos na vida dos homens. Ideias essas que entram em consonância com a aceitação do caráter científico que será proposto pela história. [...] Fatos e personagens históricos migram para o território da ficção [...] e propiciam coexistência amigável e complementar entre a História e a ficção (LAVAROTI; TEIXEIRA, 2010).

Para White (1995) a história combina dados, conceitos teóricos para explicar esses dados e uma estrutura narrativa que os apresenta como um conjunto de eventos presumivelmente ocorridos em tempos passados. Para ele, a literatura trabalha com o mundo das possibilidades, e a história, com a realidade concreta. Contudo, há uma conexão entre os dois campos, embora cada tipo de texto tenha sua linguagem específica.

Os estudos sobre diferenças e semelhanças entre o discurso histórico e o ficcional não se esgotam, são bem fundamentados e têm crescido desde o século XIX, mas não há uma conclusão. Três estudiosos se debruçaram sobre o processo de escrita da história: Hayden White, Meta-história (1973); Michel de Certeau, A escrita da história (1975); Paul Veyne, Como se escreve a história (1971).

White (2011, p. 479) afirma sobre a história:

É o sucesso da narrativa em revelar o sentido, a coerência ou a significância dos eventos que atesta a legitimidade de sua prática na historiografia. Eé o sucesso da historiografia em narrativizar o conjunto de eventos históricos que atesta o "realismo" da própria narrativa. No tipo de simbolização incorporado na narrativa histórica, os seres humanos dispõem de um instrumento discursivo pelo qual asseveram que o mundo das ações humanas é igualmente real e misterioso, ou seja, misteriosamente real.

Para White (2011, p. 482), a noção de narrativa contém uma ambiguidade do mesmo tipo que encontramos no uso do termo história:

A narrativa é, a um só tempo, um modo de discurso, uma maneira de falar e o produto produzido pela adoção desse modo de discurso. Quando este é usado para representar eventos "reais", como na "narrativa histórica", o resultado é um tipo de discurso com marcas linguísticas, gramaticais e retóricas específicas - a saber: a narrativa 
histórica. [...]. A noção do que constitui um acontecimento real se transforma não na distinção entre o falso e o verdadeiro (que é uma distinção que pertence à ordem dos discursos, não à ordem dos acontecimentos), mas antes na distinção entre o real e o imaginário (que pertence tanto à ordem dos acontecimentos como à dos discursos).

Os limites entre história e ficção, contudo, não são sempre precisos; em alguns momentos há dificuldade de se estabelecer essa fronteira, pois muitas vezes o escritor busca em fatos e personagens históricos inspiração para seus escritos ficcionais. $\mathrm{O}$ ficcionista, ao "refletir a realidade", segundo a visão marxista de Lukács, representa em seu texto a ocorrência dos fatos sociais, presentes e passados. A arte é, portanto, uma expressão do tempo e do espaço em que foi produzida, bem como resultado da interação do homem com o universo circundante.

A ficção narrativa, embora possa basear-se em fatos reais e documentação, tem seu referencial no discurso poético, nas estruturas simbólicas e utiliza o imaginário. Ela também toma para si os fatos históricos e o contexto social, mas sua abordagem é outra.

Em seu A teoria do romance, Lukács trabalha uma categoria literária a que ele dá o nome de romance histórico e estuda a transformação dos gêneros, que ele classifica como a literatura que vai do período épico até o período da burguesia, e o divide em três configurações do mundo: epopeia, tragédia e filosofia.

Para Zilberman (1997, p. 184), “a historiografia transcreve um mundo 'acabado', imutável e inalcançável, enquanto que as narrativas permitem ao leitor interferir, imaginar e recriar a história". Vista sob esse prisma, à literatura é dada a liberdade de trabalhar personagens reais e criar outros que não os estudados pela historiografia. Se nos referirmos especificamente ao gênero literário conhecido como romance histórico, podemos afirmar que este busca traçar a trajetória de seus personagens usando a história para dar a eles o cunho de personagens reais, mas com a liberdade criativa que a ficção permite.

Por sua vez, Aristóteles defendia que não era papel do narrador ser historiador, embora saibamos hoje que o narrador ficcional, muitas vezes, faça uso das informações históricas para criar sua narrativa.

No pensamento marxista, o gesto criativo do homem é transformar - mediante o trabalho - a natureza ou o mundo e, consequentemente, a si mesmo. Portanto, é a arte que cumpre esse papel. Seguindo esse pensamento, Lukács afirma que a "arte realista" é aquela que reflete a realidade, sendo esta o centro da vida e eminentemente crítica da 
vida. Arte é externalização do interior, é um reflexo da realidade, mas não é cópia. A arte realista promove o reencontro do sujeito com o mundo; por ela o homem se reconcilia com o mundo; ele se reconhece no mundo apesar de todas as contradições que este apresenta.

Para Marx, o artista não precisa de teorias, quaisquer que sejam elas, mas precisa demonstrar seu apego à realidade e seu desejo de refleti-la mediante a objetividade da vida. E mais, ela é a mediação entre o sujeito e o objeto, produzindo o reflexo artístico correto: a superação do homem pela arte.

Assim, haveria uma relação intrínseca entre ficção e particularidade, uma vez que a ficção, pelo fato de abarcar singularidade e universalidade, portanto a particularidade em si, é considerada arte. Por sua vez, a história, como ciência, também reflete a realidade, mas trabalha o real e a objetividade considerando outros parâmetros que não os artísticos.

\section{CONSIDERAÇÕES FINAIS}

Procuramos mostrar neste texto a importância de Lukács e do marxismo no estudo das artes e do desenvolvimento humano, acentuando o paralelo entre reflexo científico e reflexo artístico da realidade nas mais diversas produções do homem. Para ele a arte é um reflexo da realidade, mas não é cópia, é imitação do real. Essa mimesis é transformada e reconstruída pela arte.

Em Introdução a uma estética marxista, Lukács considera em especial a função da categoria a que ele deu o nome de particularidade, recuperando-a da dialética e tornando-a ponto central de sua obra. Para o crítico húngaro, a arte é um processo em movimento e um reflexo da realidade e é por meio dela que o homem se humaniza, uma vez que ela desperta sua sensibilidade.

Lukács suscitava controvérsias e foi foco de críticas tanto de marxistas soviéticos e chineses como de marxistas ocidentais, de liberais e de conservadores, mas seus estudos são analisados até hoje em razão de sua riqueza, complexidade e profundidade em relação à importância do homem como ser social. Seus temas filosóficos, políticos e especialmente literários e sua posição crítica e eminentemente marxista despertaram o interesse de estudiosos das mais diferentes correntes e áreas do conhecimento.

Os conceitos lukacsianos, de base marxista, tratam da ontologia, da arte e da estética, da crítica literária e da história e mostram a importância do homem - 
condicionado pelo contexto histórico e social - como partícipe de um gênero mais amplo: o gênero humano. Para Marx o trabalho é essencial e o centro da relação do homem com a sociedade, e é por meio dele que o homem se transforma de homem natural em homem social, ou seja, ele modifica a natureza com o seu trabalho. Objetivação e subjetivação surgem com esse processo.

Assim, Lukács ressalta no homem sua capacidade de modificar os destinos da humanidade em face do capitalismo, pois os objetos existem para o homem e são criados para sua satisfação. Da mesma forma, a arte é a razão de ser do homem.

Quanto à ficção e à história, podemos concluir que elas têm traços em comum bem como diferenças, embora às vezes o limite entre ambas seja quase indelével. Contudo, a história tem por foco os fatos históricos reais e já ocorridos e a ficção, apesar de ser um reflexo da realidade, permite ao artista trabalhar a imaginação. Desse modo, a ficção é uma arte, mas a ciência não o é.

\section{REFERÊNCIAS}

CERTEAU, Michel de. A escrita da história. Tradução de Maria de Lourdes Menezes. Rio de Janeiro: Forense Universitária, 1982.

LAVORATI, Carla; TEIXEIRA, Níncia Cecília Ribas Borges. Diálogos entre ficção e história: do romance histórico clássico ao novo romance histórico. Revista Odisseia, $\mathrm{n}$. 6, jul.-dez. 2010. Revista do PPGEL/UFRN.

LUKÁCS, Georg. Concretização da particularidade como categoria estética em problemas singulares (Capítulo VI). Introdução a uma estética marxista: sobre a particularidade como categoria da estética. 2. ed. Tradução de Carlos Nelson Coutinho e Leandro Konder. Rio de Janeiro: Civilização Brasileira, 1970.

A teoria do romance. Tradução de José Marcos Mariani de Macedo. São Paulo: Editora 34, 2000.

MENDONÇA, Carlos Vinícius Costa de; ALVES, Gabriela Santos. Os desafios teóricos da história e a literatura. In: Contraponto: Revista do Departamento de História e do Programa de Pós-Graduação em História do Brasil da UFPI, Teresina, v. 2, n.1, ago. 2013.

TERTULIAN, Nicolas. Lukács e o stalinismo 1. Verinotio - Revista On-line de Educação e Ciências Humanas, n. 7, ano IV, nov. 2007. Disponível em: <http://www.verinotio.org/conteudo/0.65943372031621.pdf>. Acesso em: 23 abr. 2018. 
WHITE, Hayden. Meta-história: a imaginação histórica do século XIX. São Paulo: Edusp, 1995.

A questão da narrativa na teoria histórica contemporânea. Capítulo 18 (p. 439483). In: NOVAIS, Fernando A.; SILVA, Rogerio F. da (Org.). Nova história em perspectiva: propostas e desdobramentos. São Paulo: Cosac e Naify, 2011.

ZILBERMAN, Regina. História romanceada. Gêneros de fronteira: cruzamento entre o histórico e o literário. Tradução Sandra Vasconcelos. São Paulo: Xamã, 1997.

Recebido em: 18 abr. 2018

Aceito em: 02 mai. 2018 